ISSN: 2386-3919 - e-ISSN: 2386-3927

DOI: https://doi.org/10.14201/et20203826785

\title{
LA EFICACIA DE LA ENSEÑANZA A DISTANCIA DURANTE EL CONFINAMIENTO POR COVID-19 EN LAS ZONAS DE BAJA COBERTURA DE LA ESPAÑA VACIADA. EL CASO DE SALAMANCA
}

\section{The Effectiveness of Distance Learning During Confinement by Covid-19 in Low Coverage Areas of the Empty Spain. The case of Salamanca}

María del Pilar Quicios García, Pablo Herrero Teijón y Patricia GonZález Ocejo pquicios@edu.uned.es

pherrerot@educa.jcyl.es

patricia.gonoce@educa.jcyl.es

Recibido: 10/12/2020; Aceptado: 18/12/2020; Publicado: 27/12/2020

Ref. Bibl. MARÍA DEL PILAR QUICIOS GARCÍA, PABLO HERRERO TEIJÓN y PATRICIA GONZÁLEZ OCEJO. La eficacia de la enseñanza a distancia durante el confinamiento por COVID-19 en las zonas de baja cobertura de la España vaciada. El caso de Salamanca. Enseñanza E Teaching, 38, 2-2020, 67-85.

RESUMEN: La COVID-19 es la contracción del nombre de la enfermedad nacida en diciembre de 2019 en la ciudad china de Wuhan originada por el virus SARSCoV-2 y origen de la primera pandemia mundial del siglo XXI según la OMS. La virulencia y gravedad de este virus ha tenido consecuencias en todos los ámbitos y costumbres de todo el planeta Tierra. En este artículo se presentan las modificaciones que la Covid-19 ha obligado a realizar en la docencia de la educación secundaria en una zona especialmente sensible de la Comunidad Autónoma de Castilla y León (la zona de sur y oeste de Salamanca de baja cobertura de la España vaciada). Para conocer cómo acomodar la docencia de esta zona geográfica en este nivel de enseñanza se realizó una encuesta a 294 alumnos escolarizados en Educación Secundaria Obligatoria con edades comprendidas entre 12-16 años. Igualmente se pasó la encuesta 
M. ${ }^{a}$ DEL PILAR QUICIOS GARCÍA, PABLO HERRERO TEIJÓN Y PATRICIA GONZÁLEZ OCEJO LA EFICACIA DE LA ENSEÑANZA A DISTANCIA DURANTE EL CONFINAMIENTO POR COVID-19 EN LAS ZONAS DE BAJA COBERTURA DE LA ESPAÑA VACIADA. EL CASO DE SALAMANCA

a las 261 familias de esos estudiantes. El objetivo de la encuesta era conocer con total transparencia la posibilidad de acceso de los estudiantes a las TIC para poder planificar el periodo de docencia no presencial derivado del confinamiento establecido por el Gobierno central. Los resultados de la encuesta aconsejaron modificar la enseñanza presencial por la enseñanza a través de la metodología de la enseñanza a distancia. Su oportuna puesta en marcha ha permitido desarrollar una auténtica y eficaz enseñanza personalizada e inclusiva que ha posibilitado a prácticamente la totalidad del alumnado de la España vaciada de la provincia de Salamanca superar el curso escolar 2019/2020.

Palabras clave: educación a distancia; COVID-19; España vaciada; zonas blancas NGA; zonas grises NGA; TIC; 5G.

SUMMARY: COVID-19 is the contraction of the name of the disease born in December 2019 in the Chinese city of Wuhan caused by the SARS-CoV-2 virus and origin of the first global pandemic of the 21st century according to the WHO. The virulence and severity of this virus has had consequences in all areas and habits of the entire planet Earth. This paper presents the modifications that the Covid-19 has forced to carry out in the teaching of secondary education in a particularly sensitive area of the Autonomous Community of Castilla y León (the low signal and depopulated areas of south and west Salamanca). To find out how to accommodate the teaching in this geographic area at this level of education, a survey was conducted of 294 students enrolled in Compulsory Secondary Education aged 12-16 years. The survey was also passed to the 261 families of these students. The objective of the survey was to know with total transparency the possibility of student access to ICT in order to plan the non-face-to-face teaching period derived from the confinement established by the Central Government. The results of the survey advised modifying face-to-face teaching for teaching through the methodology of distance learning. Its timely start-up has allowed the development of an authentic and effective personalized and inclusive teaching that has enabled practically all the students in depopulated areas of the province of Salamanca to pass the 2019/2020 school year.

Key words: distance education; COVID-19; depopulation; NGA white areas; NGA gray areas; TIC; 5G.

\section{INTRODUCCIÓN}

La enfermedad causada por el virus SARS-CoV-2 se ha popularizado con el nombre de coronavirus 2019 (https://www.who.int/es/emergencies/diseases/novel-coronavirus-2019) o por su contracción COVID-19 (CO significa "Corona», VI "virus», D «enfermedad» [disease, en inglés] y 19 concreta el año en el que se originó, 2019) https://www.edicionmedica.ec/secciones/salud-publica/ covid-19-nombre-oficial-de-la-enfermedad-por-el-nuevo-coronavirus-95307. 
M. ${ }^{a}$ DEL PILAR QUICIOS GARCÍA, PABLO HERRERO TEIJÓN Y PATRICIA GONZÁLEZ OCEJO

LA EFICACIA DE LA ENSEÑANZA A DISTANCIA DURANTE EL CONFINAMIENTO POR COVID-19

EN LAS ZONAS DE BAJA COBERTURA DE LA ESPAÑA VACIADA. EL CASO DE SALAMANCA

Esta enfermedad parece que surgió, por primera vez, en Wuhan (China) el 31 de diciembre de 2019 al diagnosticarse en esa ciudad numerosos casos de un nuevo tipo de neumonía (Wu et al., 2019; Zhou et al., 2020). Aquellos primeros casos de neumonía bilateral no se dieron a conocer durante sus dos primeros meses de existencia. Ese secretismo ni impidió ni detuvo su difusión, más bien surtió el efecto contrario. La globalización que caracteriza la nueva era humana (Santano, 2020), desconocedora de la virulencia infectiva del SARS-CoV-2, hizo que esta enfermedad se propagara en un cortísimo espacio de tiempo por todo el planeta. Su rapidísima transmisión, el elevado número de fallecidos, la carencia de medidas preventivas y la falta de material médico para abordarla obligaron a que el 11 de marzo de 2020 la OMS considerara esta enfermedad emergente como una pandemia mundial sin precedentes.

La OMS ha estado evaluando este brote durante todo el día y estamos profundamente preocupados tanto por los niveles alarmantes de propagación y gravedad, como por los niveles alarmantes de inacción. Por lo tanto, hemos evaluado que COVID-19 puede caracterizarse como una pandemia. (https://www.paho.org/es/ noticias/11-3-2020-oms-caracteriza-covid-19-como-pandemia)

Casi un año después de los primeros casos detectados, el SARS-CoV-2 o COVID-19 sigue constituyendo uno de los mayores desafíos a los que se enfrenta el ser humano (Yang y Wang, 2020). Este motivo ha llevado a que todos los países desarrollados hayan implementado portales para mantener permanentemente informados a sus ciudadanos en todo lo concerniente al cuidado de su salud personal y comunitaria. En España, toda la información actualizada sobre la evolución de esta enfermedad se encuentra en los portales https://covid19.gob.es/ y https:// covid19.isciii.es/.

Resulta completamente innecesario afirmar que esta pandemia ha supuesto una revolución global en todo el mundo puesto que es un hecho incuestionable e indiscutido. El COVID 19 ha cambiado las reglas de comportamiento de todas las sociedades mundiales. Ha impuesto actitudes sociosanitarias emergentes que van desde guardar una obligada distancia física entre las personas (distancia social) hasta reducir el número de contactos sociales pasando por saludar en la distancia, aprender a mostrar el cariño con nuevas manifestaciones de afecto o respeto, abonar el importe de una compra a través de estrategias que no obliguen a manipular papel moneda, adquirir bienes y servicios a través de plataformas de compra online... (Reyes, Vallejos y Quintana, 2020).

Ciertamente que esta enfermedad ha empobrecido las relaciones humanas presenciales, aunque, simultáneamente, ha enriquecido aspectos tan humanos como el lenguaje y las herramientas de comunicación ubicuas no presenciales. Así, el diccionario de la Real Academia de la lengua española, por ejemplo, ha incorporado términos y expresiones emergentes como Coronavirus, desconfinar, cuarentenar, desescalada, distopía nueva normalidad, CPR, prueba de antígenos... https://dle.rae.es/contenido/actualizaci \%C3 \%B3n-2020. 
M. ${ }^{a}$ DEL PILAR QUICIOS GARCÍA, PABLO HERRERO TEIJÓN Y PATRICIA GONZÁLEZ OCEJO LA EFICACIA DE LA ENSEÑANZA A DISTANCIA DURANTE EL CONFINAMIENTO POR COVID-19 EN LAS ZONAS DE BAJA COBERTURA DE LA ESPAÑA VACIADA. EL CASO DE SALAMANCA

Este virus, a su vez, ha modificado la deontología médica mundial. El SARSCoV-2 ha obligado a los sanitarios de todo el planeta a aplicar una medicina de guerra en tiempos de paz. Ha obligado a médicos y a enfermeras a realizar triajes selectivos impensables en las sociedades del bienestar. Igualmente, ha propiciado un cambio de valores sociales y hasta una reorganización de la atención instructiva en todas las etapas de enseñanza de todos los países.

En las etapas previas a esta pandemia, es decir, en la antigua normalidad, las sociedades científicas, las revistas profesionales, los grupos de investigación, las universidades y las empresas tecnológicas (confiados, todos ellos, en el desarrollo tecnológico mundial) centraban sus esfuerzos en expandir nuevas metodologías de enseñanza-aprendizaje virtuales (Rodríguez y Barragán, 2017), ubicuas (VázquezCano, 2015), de aplicación de la realidad y la tecnología aumentadas (Fombona, Pascual y Vázquez-Cano, 2020; Cabero, Vázquez-Cano, López-Meneses y Jaén, 2020).

El SARS-CoV-2 ha manifestado de una forma patente, una vez más, la distancia que existe entre la teoría academicista y la realidad social. Nuevamente, la realidad se ha impuesto y la brecha digital existente en múltiples lugares de muchos países ha hecho volver a esquemas formativos y de entretenimiento menos exigentes tecnológicamente. Esquemas más analógicos que digitales (Sevillano y Quicios, 2009). Esquemas digitales de primera o segunda generación. Esto es exactamente lo que ha ocurrido en las zonas de baja cobertura de la España vaciada de Castilla y León en la provincia de Salamanca.

España, en 1975, contaba con 34 millones de habitantes. En 1975 no existía la expresión España vaciada aunque paulatinamente fuera vaciándose. En el año 2020, España cuenta con casi 47 millones de habitantes repartidos de manera muy desigual por toda la superficie del país. Así, mientras que la Comunidad de Madrid ha aumentado en este periodo un $73 \%$ su población, muchas otras comunidades autónomas han perdido más de un $15 \%$ de sus habitantes (INE, https://www. epdata.es/datos/despoblacion-espana-datos-estadisticas/282).

El conjunto de provincias que no solo no han ganado población, sino que la han perdido como consecuencia de la transformación económica y social del país o como consecuencia de los movimientos poblacionales desde las zonas rurales hacia las grandes ciudades, se conoce con el nombre de la España vaciada (Figura 1). Actualmente la España vaciada es un hecho. Es el producto de un proceso no abordado ni social ni políticamente en sus inicios (García-Jiménez, 2020). 


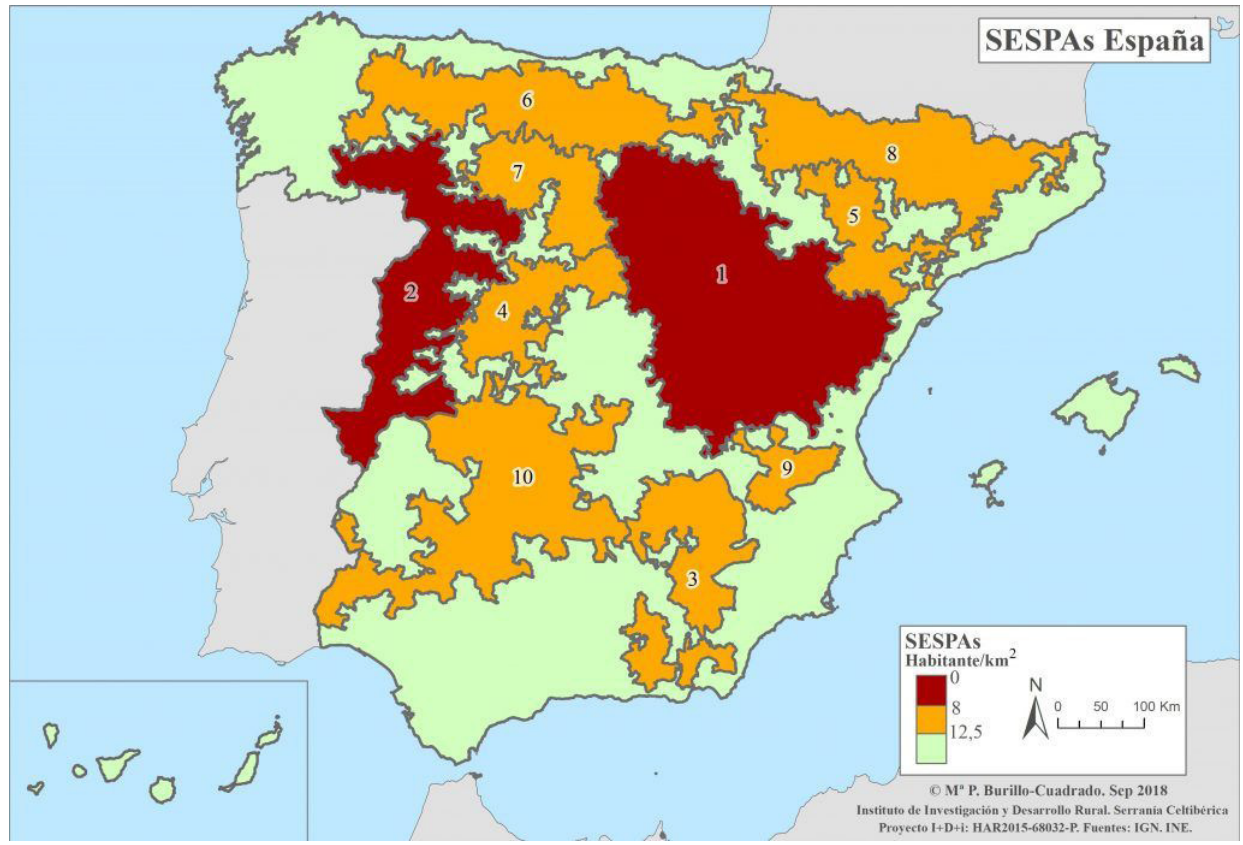

Figura 1. Zonificación de la España vaciada. Obtenido de Burillo y Burillo (2019).

La España vaciada, además de por ausencia de población, se caracteriza por falta de recursos e inversiones (Fernández, 2020). Una de las carencias que más claramente se ha manifestado durante la pandemia por COVID-19 ha sido la cobertura digital de los territorios menos habitados (Vázquez y Cambero, 2020). Este hecho ha visibilizado la gran brecha, pobreza, silencio o abandono digital que existe en muchas de las poblaciones de la España vaciada.

La realidad descrita no es nueva pero sí visible, explícitamente, por primera vez. Se afirma que este hecho no es nuevo porque el Ministerio de Asuntos Económicos y Transformación Digital elabora anualmente un Informe de cobertura de todas las localidades de España. Ese informe se redacta partiendo de los datos ofrecidos por todos los operadores y plataformas tecnológicas del país (https:// avancedigital.gob.es/banda-ancha/cobertura/Documents/Cobertura-BA-2019.pdf). En el informe presentado en 2019 se han delimitado las zonas por su amplitud de banda ancha. Así, se han definido:

- Zonas blancas NGA; es decir, aquellas zonas que no disponen de cobertura de redes de banda ancha de nueva generación.

Además de no disponer de esta cobertura actualmente, en estas zonas no existen previsiones para su dotación por algún operador en el plazo de tres años si se parte del análisis de planes de inversión creíbles. 
M. ${ }^{a}$ DEL PILAR QUICIOS GARCÍA, PABLO HERRERO TEIJÓN Y PATRICIA GONZÁLEZ OCEJO LA EFICACIA DE LA ENSEÑANZA A DISTANCIA DURANTE EL CONFINAMIENTO POR COVID-19 EN LAS ZONAS DE BAJA COBERTURA DE LA ESPAÑA VACIADA. EL CASO DE SALAMANCA

La presencia de zonas blancas se corresponde, en muchas ocasiones, con zonas de la España vaciada (Fuentes, 2019; Giménez, 2017). Las zonas blancas NGA constituyen una verdadera limitación para el desarrollo de estas localidades.

- Zonas grises NGA; es decir, aquellas zonas que solo disponen de cobertura de banda ancha de nueva generación. También se denominan zonas grises NGA a las zonas que está previsto que estén dotadas de banda ancha de nueva generación en el plazo de tres años por parte de un solo operador.

Un claro ejemplo de las limitaciones a las que se enfrenta la población que todavía habita la España vaciada se ha producido en el ejercicio del derecho humano de acceso a la educación de los estudiantes españoles que habitan las zonas de baja cobertura de amplitud de banda ancha. Estos estudiantes, desde la declaración del estado de alarma en todo el territorio nacional por parte del Gobierno mediante el Real Decreto 463/2020, de 14 de marzo, han tenido que recibir su instrucción académica en unos hogares que no estaban preparados para responder a las indicaciones del Ministerio de Educación y Formación Profesional.

El Ministerio de Educación y Formación Profesional, desde el 14 de marzo de 2020, ha publicado toda una serie de legislación con el objetivo de fijar unas directrices formativas de aplicación en todo el país. De entre todos estos documentos legislativos destacan, especialmente, los acuerdos generados en el seno de la Conferencia Sectorial de Educación. En este ente se fijan las directrices específicas de actuación acordada por etapas o enseñanzas. Así, se dictan directrices para la Educación Primaria, Educación Secundaria Obligatoria, Bachillerato, Formación Profesional y Enseñanzas Artísticas y Deportivas de manera diferenciada. Estas directrices se dictaron para ejecutarse durante el tercer trimestre del curso escolar 2019-2020 y el inicio del curso escolar 2020-2021 (https://www.boe.es/buscar/act. php?id=BOE-A-2020-4609\#ai-3).

Corresponde a cada Comunidad Autónoma desarrollar los acuerdos generales de la Conferencia Sectorial de Educación dependientes del Ministerio de Educación y Formación Profesional (de conformidad con las competencias atribuidas en sus Estatutos de Autonomía). En el caso que ocupa a este artículo, la Comunidad Autónoma de Castilla y León ha sido la responsable de adecuar las directrices fijadas por el Gobierno central para el desarrollo de la actividad docente durante este periodo marcado por la enfermedad COVID-19. Esta tarea, desde Castilla y León, se ha realizado emitiendo la Orden EDU/308/2020, de 14 de marzo.

La Orden EDU/308/2020, de 14 de marzo, legisló el funcionamiento de los centros docentes no universitarios de la Comunidad de Castilla y León cuya actividad docente presencial y actividades extraescolares fueron suspendidas como consecuencia del coronavirus, COVID-19. En este mismo esquema legislativo, el 23 de marzo de 2020, se decretó el cierre de todos los centros docentes y la obligatoriedad de continuar las actividades lectivas de forma no presencial mientras durase el estado de alarma. Es preciso indicar para los lectores no familiarizados con el calendario académico de la enseñanza primaria y secundaria que el cierre de 
M. ${ }^{a}$ DEL PILAR QUICIOS GARCÍA, PABLO HERRERO TEIJÓN Y PATRICIA GONZÁLEZ OCEJO

LA EFICACIA DE LA ENSEÑANZA A DISTANCIA DURANTE EL CONFINAMIENTO POR COVID-19

EN LAS ZONAS DE BAJA COBERTURA DE LA ESPAÑA VACIADA. EL CASO DE SALAMANCA

los centros docentes no universitarios coincidió cronológicamente con el final de la segunda evaluación.

El desarrollo legislativo obligó a que la segunda evaluación de la enseñanza primaria y secundaria de la Comunidad Autónoma de Castilla y León se desarrollase siguiendo la Instrucción de 26 de marzo de 2020, de la Dirección General de Centros, Planificación y Ordenación Educativa, relativa a la realización de la segunda evaluación del curso académico 2019/2020. Para dar respuesta a la Instrucción de 26 de marzo de 2020, de la Dirección General de Centros, Planificación y Ordenación Educativa, la Junta de Castilla y León puso a disposición de la comunidad educativa toda una serie de recursos. El más importante, entre todos ellos, fue la creación de un aula virtual por centro educativo (https://www.educa.jcyl.es/profesorado/es/ recursos-aula/recursos-educativos-online/aprendiendo-casa-hora-educativa-cyltv).

Los equipos directivos de los centros educativos de la Comunidad Autónoma, por su parte, para poder ejercer su docencia de forma no presencial elaboraron toda una serie de actuaciones dirigidas a asegurar el ejercicio del derecho humano y constitucional del alumnado a la educación. Para conseguir el ejercicio de este derecho fundamental de todo ciudadano, los equipos directivos buscaron los canales y procedimientos necesarios para garantizar que la información de las tareas propuestas llegase a todas las familias. El fin que perseguía esta actividad era el procurar que el alumnado mantuviera diariamente una rutina y unos hábitos de estudio en sus domicilios a través de la realización de las tareas diseñadas de manera secuencial.

Como puede deducirse por lo expuesto en este artículo, la finalidad perseguida representaba un gran reto en determinadas zonas de la Comunidad Autónoma de Castilla y León, concretamente, en las zonas blancas y grises de cobertura englobadas en la más perfecta definición de la España vaciada. Estas zonas blancas y grises de cobertura correspondían, en parte, a la zona más rural de la provincia de Salamanca. Terminada la segunda evaluación de Educación Primaria y Secundaria en estado de alarma, se redactó una nueva instrucción legislativa para ejecutar en el tercer trimestre del curso 2019/2020.

El tercer trimestre del curso estuvo regulado por la Instrucción de 17 de abril de 2020, de la Dirección General de Centros, Planificación y Ordenación Educativa de la Consejería de Educación de la Junta de Castilla y León. Esta instrucción diseñaba la actividad educativa durante el tercer trimestre y la evaluación final del curso académico 2019-2020. En ella, literalmente se indicaba que:

En aras de garantizar el derecho a la educación y el mantenimiento de la equidad de nuestro sistema educativo, los centros velarán por la situación del alumnado en relación con las posibilidades de continuar su aprendizaje. En los casos donde sea necesario, los centros docentes, a través del equipo directivo, darán cuenta al inspector encargado del centro de los alumnos que presenten dificultades para mantener una relación regular durante el periodo en que se ha desarrollado la actividad lectiva no presencial, hasta la finalización del segundo trimestre. Todo ello con el fin de que se puedan adoptar las medidas pedagógicas y organizativas que sean necesarias. 


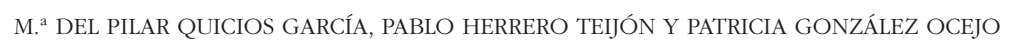
LA EFICACIA DE LA ENSEÑANZA A DISTANCIA DURANTE EL CONFINAMIENTO POR COVID-19 EN LAS ZONAS DE BAJA COBERTURA DE LA ESPAÑA VACIADA. EL CASO DE SALAMANCA

Tras detectarse casos de alumnos que no podían conectarse a internet, la Junta de Castilla y León inició un programa de reparto de tarjetas SIM para el uso de estos alumnos (Europapress, 2020). Esta decisión, siendo loable, una vez más era ineficaz. Se dotaba de tarjetas SIM a alumnos que no tenían hardware en los que ubicar las tarjetas. Para paliar esta debilidad, varios centros educativos, por su parte, pusieron a disposición de sus alumnos ordenadores de sus propios centros. Este hardware fue repartido con el concurso de los cuerpos y fuerzas de seguridad del Estado (El Norte de Castilla, 19/04/2020; Europapress, 29/04/2020). Afortunadamente no todos los estudiantes necesitaron acceder a esta estrategia de reparto de material informático. Si hubiera sido una necesidad masiva, hubiera resultado imposible darles una respuesta en un periodo de tiempo corto y los resultados académicos de la segunda evaluación se hubieran visto comprometidos.

La forma de conocer los destinatarios de tal hardware se explica en el apartado Método de este artículo.

\section{MÉTODO}

En diecisiete localidades de menos de 1500 habitantes del sur y del oeste de la provincia de Salamanca se realizó a 294 alumnos escolarizados en educación secundaria obligatoria con edades comprendidas entre 12-16 años una encuesta a través de un formulario Google Forms. Estos formularios se rellenaron desde los ordenadores de sus domicilios o desde los ordenadores del centro educativo.

Tras esta, se aplicó una segunda encuesta a las 261 familias de los alumnos anteriormente encuestados. Las familias también rellenaron un formulario Google Forms.

El objetivo que se perseguía al realizar la encuesta a las familias era garantizar la equidad del sistema educativo español en la enseñanza obligatoria y garantizar el ejercicio del derecho humano y constitucional de acceso de toda persona a la educación. Por todo ello se necesitaba disponer de la información de todas las familias. Para asegurar la participación de todas ellas, aquellas que no respondieron la encuesta fueron llamadas telefónicamente y a través de este medio se rellenaron sus formularios. Se actuó exactamente igual cuando se comprobó que las respuestas dadas por los estudiantes no coincidían con las dadas por sus familias. Es decir, puesto que se necesitaba conocer con total transparencia la posibilidad de acceso de los estudiantes a las TIC se buscaron las respuestas de las familias de los alumnos de las formas más creativas.

Las preguntas contenidas en los formularios se agruparon en 3 grandes grupos:

- Identificación del alumno y/o de la familia.

- Posesión y nivel de uso de medios informáticos y tecnológicos.

- Participación en redes sociales y uso de aplicaciones de mensajería instantánea. 
M. ${ }^{a}$ DEL PILAR QUICIOS GARCÍA, PABLO HERRERO TEIJÓN Y PATRICIA GONZÁLEZ OCEJO

LA EFICACIA DE LA ENSEÑANZA A DISTANCIA DURANTE EL CONFINAMIENTO POR COVID-19

EN LAS ZONAS DE BAJA COBERTURA DE LA ESPAÑA VACIADA. EL CASO DE SALAMANCA

Excepto las preguntas de identificación personal, todas las demás se formularon a través de variables dicotómicas. Esta forma de actuar era la más directa y la más eficaz. Es preciso indicar que el único objetivo perseguido por la encuesta era conocer la posibilidad real de acceso a la tecnología de los estudiantes. No se quería realizar ningún proyecto de investigación sobre la temática, de ahí que la muestra de estudio y la población coincidieran y no fuera excesivamente amplia.

\section{Resultados}

Las preguntas contenidas en las encuestas y sus resultados fueron los siguientes:

Medios tecnológicos presentes en el hogar de los alumnos

\begin{tabular}{l|c|c|c|c}
\hline \multicolumn{1}{c|}{ Ítems } & Sí & NO & $\%$ Sí & $\%$ NO \\
\hline Existe ordenador en el domicilio & 261 & 33 & 88,78 & 11,22 \\
\hline Posee ordenador propio el estudiante & 176 & 85 & 67,43 & 32,57 \\
\hline Posee tablet propia el estudiante & 149 & 145 & 50,68 & 49,32 \\
\hline Posee teléfono móvil propio el estudiante & 294 & 0 & 100,00 & 0,00 \\
\hline Cuenta el domicilio con conexión a internet & 243 & 51 & 82,65 & 17,35 \\
\hline $\begin{array}{l}\text { Cuentan los dispositivos digitales del hogar con } \\
\text { datos ilimitados }\end{array}$ & 93 & 150 & 38,27 & 61,73 \\
\hline
\end{tabular}

Nivel de desempeño digital de los alumnos

\begin{tabular}{l|c|c|c|c}
\hline \multicolumn{1}{c|}{ Ítems } & Sí & NO & \%Sí & $\%$ NO \\
\hline El alumno sabe usar la plataforma virtual & 238 & 56 & 80,95 & 19,05 \\
\hline El alumno sabe usar el correo corporativo & 255 & 39 & 86,73 & 13,27 \\
\hline El alumno se desenvuelve con el paquete office & 259 & 35 & 88,10 & 11,90 \\
\hline Usa la aplicación WhatsApp & 294 & 0 & 100,00 & 0,00 \\
\hline Tiene cuenta de Facebook & 76 & 185 & 29,12 & 70,88 \\
\hline Tiene cuenta de Instagram & 241 & 53 & 81,97 & 18,03 \\
\hline
\end{tabular}


M. ${ }^{a}$ DEL PILAR QUICIOS GARCÍA, PABLO HERRERO TEIJÓN Y PATRICIA GONZÁLEZ OCEJO LA EFICACIA DE LA ENSEÑANZA A DISTANCIA DURANTE EL CONFINAMIENTO POR COVID-19 EN LAS ZONAS DE BAJA COBERTURA DE LA ESPAÑA VACIADA. EL CASO DE SALAMANCA

Nivel de desempeño digital de las familias

\begin{tabular}{l|c|c|c|c}
\hline \multicolumn{1}{c|}{ Ítems } & SÍ & NO & \%SÍ & $\%$ NO \\
\hline La familia entra en la plataforma virtual & 195 & 66 & 74,71 & 25,29 \\
\hline La familia presenta dificultades para ayudar a su hijo & 104 & 157 & 39,85 & 60,15 \\
\hline Saben usar el paquete office & 168 & 93 & 64,37 & 35,63 \\
\hline Usan la aplicación WhatsApp & 259 & 2 & 99,23 & 0,77 \\
\hline Tienen cuenta de Facebook & 227 & 34 & 86,97 & 13,03 \\
\hline Tienen cuenta de Instagram & 88 & 173 & 33,72 & 66,28 \\
\hline
\end{tabular}

De la encuesta realizada al alumnado se extrajeron los siguientes resultados:

- Sobre el acceso a un ordenador: un 89 \% del alumnado disponía de ordenador en casa, aunque casi un tercio de ese alumnado, es decir, el $32 \%$, tenía que compartir el ordenador con el resto de los miembros de la familia.

- Sobre el acceso a una tablet: tan solo el 50 \% del alumnado tenía acceso a ella.

- Sobre el acceso a un teléfono móvil: el 100 \% del alumnado tenía un teléfono móvil.

- Sobre el acceso a internet: un $82 \%$ del alumnado sometido a estudio tenía posibilidad de conectarse a internet, a pesar de que más de un tercio del mismo, exactamente un $38 \%$, estaba condicionado por el límite de uso de datos móviles.

- Sobre el manejo habitual de WhatsApp e Instagram: la totalidad de los alumnos utiliza WhatsApp y una gran mayoría de ellos, casi el $82 \%$, declaró tener cuenta de Instagram.

- Sobre el manejo del aula virtual: un 81 \% contestó que sabía manejar el aula virtual, no obstante, manifestaron tener problemas para acceder y para cargar archivos por la limitación de tamaño de los mismos.

- Sobre el manejo del correo electrónico educacyl: un 87 \% contestó que sabía manejarlo.

- Sobre el manejo de las Herramientas de Office 365: un 88 \% contestó que sabía manejarlas.

De la encuesta realizada a las familias se extrajeron los siguientes resultados:

- Tan solo 6 de cada 10 familias podrían ayudar a sus hijas/os en tareas relacionadas con informática por falta de conocimientos.

- Sobre el manejo habitual de WhatsApp e Instagram: prácticamente la totalidad de las familias manifestaba utilizar WhatsApp, pero solo 1 de cada 3 tenía una cuenta de Instagram. 
M. ${ }^{a}$ DEL PILAR QUICIOS GARCÍA, PABLO HERRERO TEIJÓN Y PATRICIA GONZÁLEZ OCEJO

LA EFICACIA DE LA ENSEÑANZA A DISTANCIA DURANTE EL CONFINAMIENTO POR COVID-19

EN LAS ZONAS DE BAJA COBERTURA DE LA ESPAÑA VACIADA. EL CASO DE SALAMANCA

- Hasta un $74 \%$ de las familias entraba en el aula virtual. Los problemas que señalaron para usar el aula virtual eran que tenían demasiadas tareas, problemas de conexión, falta de cámara para ver al profesor, falta de tiempo para atender a sus hijas/os con las tareas.

\section{DISCUSIÓN}

Los resultados encontrados aconsejaron descartar completamente por inviable la enseñanza ubicua como metodología docente durante el confinamiento. Los resultados también desaconsejaron la enseñanza exclusivamente virtual. Ante estos dos hechos ciertos se decidió realizar la instrucción a través de la metodología de la enseñanza a distancia.

En la Instrucción de 17 de abril de 2020, de la Dirección General de Centros, Planificación y Ordenación Educativa de la Consejería de Educación de la Junta de Castilla y León, relativa al desarrollo de la actividad educativa durante el tercer trimestre y la evaluación final del curso académico 2019-2020, se detalla en el apartado quinto:

Al finalizar el curso, los docentes que imparten clase a cada grupo llevarán a cabo la evaluación final de los resultados alcanzados por el alumnado, debiendo tener en consideración la situación vivida durante este tercer trimestre para realizar la citada evaluación. En la valoración global del alumnado se tendrán fundamentalmente en consideración los resultados de las dos primeras evaluaciones y, a partir de ellos, se valorarán de forma positiva todas las actividades y pruebas realizadas por el alumnado durante el tercer trimestre.

Por tanto, la calificación final de los estudiantes del tercer trimestre solo podía contar positivamente. Esto quiere decir que en muchos casos las calificaciones del tercer trimestre sirvieron para que los alumnos que tenían alguna de las dos primeras evaluaciones suspensas pudieran recuperarlas y aprobar las distintas asignaturas y, por extensión, el curso académico. Esta decisión que ayudó a algunos estudiantes a superar el curso también fue desmotivadora para los estudiantes que tenían las dos primeras evaluaciones aprobadas. Estos estudiantes sabían que no podían ser suspendidos puesto que ya tenían aprobada la asignatura y muchos de ellos dieron por terminado su curso académico con el inicio de las vacaciones de Semana Santa.

\section{EFICACIA DURANTE EL CONFINAMIENTO POR COVID DE LA ENSEÑANZA A DISTANCIA}

Tradicionalmente, y de manera errónea, se identifica enseñanza a distancia con estudios universitarios cuando siempre ha existido una oferta formativa a través de esta metodología previa al mundo universitario. Como ejemplo se 
M. ${ }^{a}$ DEL PILAR QUICIOS GARCÍA, PABLO HERRERO TEIJÓN Y PATRICIA GONZÁLEZ OCEJO LA EFICACIA DE LA ENSEÑANZA A DISTANCIA DURANTE EL CONFINAMIENTO POR COVID-19 EN LAS ZONAS DE BAJA COBERTURA DE LA ESPAÑA VACIADA. EL CASO DE SALAMANCA

plasma el bachillerato a distancia (https://cuadernodeorientacion.educa2.madrid. org/educacion-personas-adultas/ensenanza-distancia/bachillerato-distancia).

Estas enseñanzas están reguladas por la Orden 3357/2016, de 17 de octubre, de la Consejería de Educación, Juventud y Deporte, modificada por la Orden 873/2018, de 26 de marzo (BOCM de 9 de abril) de la Consejería de Educación e Investigación, por la que se ordenan y organizan para las personas adultas las enseñanzas del Bachillerato en los regímenes nocturno y a distancia en la Comunidad de Madrid. Para acceder a estos estudios es necesario ser mayor de 18 años o cumplirlos en el año natural en que comience el curso académico. En caso de tener entre 16 y 18 años, hay que acreditar fehacientemente que se está trabajando o que se es deportista de alto rendimiento.

Y la enseñanza secundaria obligatoria a distancia dirigida a mayores de edad http://www.madrid.org/dat_este/supe/ensenanzas-adultos/a_distancia.html

Las enseñanzas para la obtención del título de Graduado en Educación Secundaria Obligatoria por personas adultas podrán impartirse en el régimen presencial y en el de distancia. Los alumnos de ambos regímenes serán considerados alumnos oficiales a todos los efectos. (art. 4 Orden 3888/2008)

Algunos ejemplos no exhaustivos, pero sí ilustrativos, de formación a través de la metodología de la enseñanza a distancia previos a la constitución de la primera Universidad a Distancia en España ${ }^{1}$ quedan recogidos en la Tabla 1.

En esta tabla solo se recogen acciones formativas desplegadas por la enseñanza a distancia desde 1728 hasta un siglo antes de la pandemia del COVID-19, 1919 (García Aretio, 1999).

\section{TABLA 1}

Acontecimientos reseñables en la génesis de la Educación a Distancia hasta un siglo antes de la pandemia COVID-19

\begin{tabular}{|c|c|l|}
\hline Año & Lugar & \multicolumn{1}{|c|}{ Acontecimiento } \\
\hline $\mathbf{1 7 2 8}$ & Boston & $\begin{array}{l}\text { Caleb Phillips en la Gaceta de Boston anuncia curso de taquigrafía } \\
\text { a distancia. }\end{array}$ \\
\hline
\end{tabular}

1. Siendo exhaustivos, puede afirmarse que la Universidad Nacional a Distancia (UNED) no fue la primera universidad a distancia de España. Es cierto que fue la primera universidad a distancia que se materializó, aunque su germen se encuentra en la Universidad Libre a Distancia (UNILAD), proyecto de universidad que trataría de "recoger a los alumnos de enseñanza libre de las universidades, suprimiendo tal modalidad de enseñanza" (García Aretio, 2016, p. 13). Además de "servir de catalizador de la reforma de la universidad española que se recogía en la Ley General de Educación (LGE) de 1970» (García Aretio, 2016, p. 10).

La UNILAND fue una institución educativa ideada en los primeros años setenta del pasado siglo XX que no llegó a materializarse, aunque su filosofía constituyente se mantuviera en el decreto fundacional de la UNED de agosto de 1972. 
M. ${ }^{a}$ DEL PILAR QUICIOS GARCÍA, PABLO HERRERO TEIJÓN Y PATRICIA GONZÁLEZ OCEJO

LA EFICACIA DE LA ENSEÑANZA A DISTANCIA DURANTE EL CONFINAMIENTO POR COVID-19

EN LAS ZONAS DE BAJA COBERTURA DE LA ESPAÑA VACIADA. EL CASO DE SALAMANCA

\begin{tabular}{|c|c|c|}
\hline Año & Lugar & Acontecimiento \\
\hline 1833 & Suecia & $\begin{array}{l}\text { A. J. Meuller en el periódico Lunds Weckoblad ofrece clases de } \\
\text { composición a través del correo. }\end{array}$ \\
\hline 1836 & Inglaterra & $\begin{array}{l}\text { La Universidad de Londres adopta la modalidad de educación a } \\
\text { distancia como sistema libre y abierto de estudio. Solo se realizan } \\
\text { exámenes y confieren grados quedando excluida la labor docente. }\end{array}$ \\
\hline 1840 & Inglaterra & $\begin{array}{l}\text { Isaac Pitman a través del correo gestiona un sistema de taquigrafía } \\
\text { basado en tarjetas de intercambio. Germen de la educación a } \\
\text { distancia. }\end{array}$ \\
\hline 1843 & Inglaterra & Fundación de la Phonographic Correspondence Society. \\
\hline 1856 & Alemania & $\begin{array}{l}\text { Fundación del Institut Toussaint et Langenscheidt, primer instituto } \\
\text { de enseñanza de lenguas por correspondencia. En su docencia } \\
\text { usa material diseñado para el autoestudio. }\end{array}$ \\
\hline 1858 & Londres & $\begin{array}{l}\text { Expedición de primeros diplomas universitarios a estudiantes } \\
\text { externos a la Universidad. }\end{array}$ \\
\hline 1858 & Londres & $\begin{array}{l}\text { Nacimiento de instituciones y colleges dependientes de } \\
\text { la Universidad de Londres que imparten enseñanza por } \\
\text { correspondencia. }\end{array}$ \\
\hline 1858 & Pensilvania & Creación de las escuelas internacionales por correspondencia. \\
\hline 1858 & $\begin{array}{l}\text { Ithaca } \\
(\mathrm{N} . \mathrm{Y} .)\end{array}$ & Utilización del término Universidad por correspondencia. \\
\hline 1873 & Boston & $\begin{array}{l}\text { Creación de la Sociedad para el fomento de los estudios en casa. } \\
\text { Dirigida a mujeres. }\end{array}$ \\
\hline 1873 & Baltimore & Creación de las Escuelas de Calvert. Dirigida a niños. \\
\hline 1878 & Edimburgo & $\begin{array}{l}\text { Fundación del Skerry's College para preparar examen del Servicio } \\
\text { Civil. }\end{array}$ \\
\hline 1884 & Londres & $\begin{array}{l}\text { Fundación del Foulks Lynch Correspondence Tuition Service, } \\
\text { formaba especialistas en contabilidad. }\end{array}$ \\
\hline 1884 & Berlín & $\begin{array}{l}\text { Diseño del Rutinisches Fernlebrinstitut, dirigido a la obtención } \\
\text { del Habitur. Curso previo al ingreso en la Universidad. }\end{array}$ \\
\hline 1885 & Nueva York & $\begin{array}{l}\text { Chautauqua Institute. Impartición de programas de formación de } \\
\text { maestros durante el verano con sesiones presenciales los domingos. } \\
\text { El resto de la preparación se realizaba por correspondencia. }\end{array}$ \\
\hline 1887 & Cambridge & Fundación de la University Correspondence College. \\
\hline 1889 & Kingston & Se crea la Queen's University de Kingston (Ontario). \\
\hline
\end{tabular}


M. ${ }^{a}$ DEL PILAR QUICIOS GARCÍA, PABLO HERRERO TEIJÓN Y PATRICIA GONZÁLEZ OCEJO LA EFICACIA DE LA ENSEÑANZA A DISTANCIA DURANTE EL CONFINAMIENTO POR COVID-19 EN LAS ZONAS DE BAJA COBERTURA DE LA ESPAÑA VACIADA. EL CASO DE SALAMANCA

\begin{tabular}{|c|c|c|}
\hline Año & Lugar & Acontecimiento \\
\hline 1890 & Pensilvania & Periódico Minning Herald. Curso sobre medidas de seguridad. \\
\hline 1890 & N. Zelanda & University of New Zelanda examina a estudiantes externos. \\
\hline 1891 & Francia & Creación del Centro École chez soi. \\
\hline 1891 & Chicago & Primera referencia a enseñanza universitaria por correspondencia. \\
\hline 1891 & Wisconsin & La Universidad de Wisconsin establece curso por correspondencia. \\
\hline 1891 & Pensilvania & Creación de la International Correspondence Schools de Scranton. \\
\hline 1892 & Chicago & $\begin{array}{l}\text { Creación de la Universidad de Chicago. Fundación del External } \\
\text { Studies Departament (Departamento de enseñanza por } \\
\text { correspondencia). }\end{array}$ \\
\hline 1894 & $\begin{array}{l}\text { Alemania. } \\
\text { Berlín }\end{array}$ & $\begin{array}{l}\text { Rustinches Fernlebrinstitut ayuda en la preparación de estudiantes } \\
\text { para el examen de acceso a la Universidad. }\end{array}$ \\
\hline 1894 & Francia & $\begin{array}{l}\text { Joseph William Knipe, preparador del Certificated Teachers } \\
\text { Examination (Germen de los cursos de Wolsey Hall) para ejercer } \\
\text { el magisterio. }\end{array}$ \\
\hline 1898 & Suecia & $\begin{array}{l}\text { Hermods Korrespondensinstitut a través de la Casa Hermods } \\
\text { ofrece por correspondencia curso de teneduría de libros. }\end{array}$ \\
\hline 1898 & Suecia & Brevskola-NKI enseña en el nivel secundario. \\
\hline 1899 & Alemania & $\begin{array}{l}\text { Método Rustin. Experiencia de desarrollo y distribución de } \\
\text { materiales autoinstructivos. }\end{array}$ \\
\hline 1903 & España & Julio Cervera Baviera crea la Escuela libre de ingenieros. \\
\hline 1905 & Baltimore & $\begin{array}{l}\text { La escuela privada Calvert School crea el Departamento } \\
\text { de Formación en el Hogar (experiencia inicial de enseñanza } \\
\text { elemental a domicilio). }\end{array}$ \\
\hline 1907 & Canadá & $\begin{array}{l}\text { La Universidad de Saskatchewan posibilita formación a través de } \\
\text { la Better Farming, los Homemaker short courses y el Canadian } \\
\text { Youth Vocational Training Workshops (modalidades de educación } \\
\text { a distancia). }\end{array}$ \\
\hline 1910 & Australia & $\begin{array}{l}\text { W. A. Grundy, inspector mayor de Sanidad de Nueva Gales del Sur } \\
\text { (Australia) imparte clases por correspondencia con cierto éxito. }\end{array}$ \\
\hline 1910 & Australia & $\begin{array}{l}\text { Clases por correspondencia destinadas a la formación de } \\
\text { profesores. }\end{array}$ \\
\hline 1911 & Australia & Fundación de la Universidad de Queensland. \\
\hline
\end{tabular}


M. ${ }^{a}$ DEL PILAR QUICIOS GARCÍA, PABLO HERRERO TEIJÓN Y PATRICIA GONZÁLEZ OCEJO

LA EFICACIA DE LA ENSEÑANZA A DISTANCIA DURANTE EL CONFINAMIENTO POR COVID-19 EN LAS ZONAS DE BAJA COBERTURA DE LA ESPAÑA VACIADA. EL CASO DE SALAMANCA

\begin{tabular}{|c|c|l|}
\hline Año & Lugar & \multicolumn{1}{|c|}{ Acontecimiento } \\
\hline 1911 & Brisbane & $\begin{array}{l}\text { University of Queensland autorizada para cursos por } \\
\text { correspondencia. }\end{array}$ \\
\hline 1914 & Noruega & $\begin{array}{l}\text { Norsk Correspondanseskole. Primera institución de educación a } \\
\text { distancia noruega. }\end{array}$ \\
\hline 1914 & Alemania & Fenschule Jena. Primera institución de educación a distancia. \\
\hline 1914 & Francia & $\begin{array}{l}\text { Definición de enseñanza por correspondencia en l'École Speciale } \\
\text { des Trabaux Publics du Bâtment et de l'Industrie en su publicación } \\
\text { L'Enseignement par correspondence. }\end{array}$ \\
\hline 1914 & $\begin{array}{l}\text { Victoria } \\
\text { (Australia) }\end{array}$ & $\begin{array}{l}\text { Estudios por correspondencia supervisados. Enseñanza a niños a } \\
\text { través de la correspondencia. }\end{array}$ \\
\hline 1919 & Vancouver & $\begin{array}{l}\text { Enseñanza por correspondencia a niños alejados de las escuelas } \\
\text { financiada públicamente. }\end{array}$ \\
\hline
\end{tabular}

Fuente: Elaboración propia a partir de García Aretio (1999).

Del análisis de esta Tabla 1 puede deducirse que la educación a distancia utilizó técnicas, instrumentos, procedimientos y canales de comunicación muy diversos para su enseñanza. Esa amplitud de herramientas fue paulatinamente atrayendo seguidores tanto entre los profesionales de la enseñanza como entre las poblaciones que podían utilizar sus servicios formativos sin abandonar sus domicilios y sus tareas cotidianas. Es decir, la educación a distancia paulatinamente fue ganando adeptos, entre otros motivos, porque conseguía los fines que se proponía.

La consecución de las metas previstas se alcanzaba, en gran medida, porque «una parte considerable del éxito de la educación a distancia se basa en la calidad de los materiales y medios didácticos utilizados» (Martín y Ahijado, 1999, p. 22), es decir, en su enseñanza.

Nuevamente del análisis de la tabla precedente puede deducirse la atracción del mundo educativo por esta metodología de formación. «Muestra de esta afirmación es que comenzaran a convocarse numerosos encuentros internacionales y nacionales sobre la temática» (Rumble y Harry, 1982, p. 24).

Descartadas las posibilidades de la enseñanza ubicua y la enseñanza digital en las zonas de baja cobertura de banda ancha de Salamanca hubo que recurrir a la enseñanza a distancia. El hecho de acudir a esta metodología formativa se encontraba en la evolución que habían tenido los materiales a lo largo de la historia de la educación a distancia. Aparici (1999, p. 181) señalaba cuatro etapas:

- Primera etapa: caracterizada por el dominio del material impreso, textos y manuales, por correspondencia e intercambio de documentos.

- Segunda etapa: que denominamos analógica, caracterizada por la utilización de televisión, vídeos y programas radiofónicos. 
M. ${ }^{\text {a }}$ DEL PILAR QUICIOS GARCÍA, PABLO HERRERO TEIJÓN Y PATRICIA GONZÁLEZ OCEJO LA EFICACIA DE LA ENSEÑANZA A DISTANCIA DURANTE EL CONFINAMIENTO POR COVID-19 EN LAS ZONAS DE BAJA COBERTURA DE LA ESPAÑA VACIADA. EL CASO DE SALAMANCA

- Tercera etapa: se incorpora la informática a los procesos de producción tecnológica de materiales.

- Cuarta etapa: que denominamos digital, y donde se integran los diferentes medios tecnológicos a través de redes como Internet $u$ otros canales de distribución digital.

Así, en las zonas blancas y grises NGA, es decir, en las zonas que no disponían de cobertura suficiente de redes de banda ancha de nueva generación, hubo que usar las tecnologías de primera generación (material impreso, textos y manuales, por correspondencia e intercambio de documentos).

\section{CONCLUSIONES}

Este artículo no hubiera tenido sentido escribirlo si las administraciones educativas hubieran conocido la realidad social y tecnológica de todas las zonas de la Comunidad Autónoma de Castilla y León. Sin embargo, la distancia entre la realidad social y la visión burocrática de los legisladores de la Dirección General de Centros, Planificación y Ordenación educativa de la Junta de Castilla y León obligó a todos los docentes destinados en zonas de baja cobertura NGA de la provincia de Salamanca a acometer actuaciones urgentes para poder dar respuesta a las exigencias legislativas durante el periodo de confinamiento por COVID-19.

Las primeras respuestas corrieron a cargo de los equipos directivos de los centros educativos ubicados en las zonas blancas y grises NGA existentes en las zonas de baja cobertura de la España vaciada. Sin la determinación de estos equipos directivos, los estudiantes de esta parte de la España vaciada no podrían haber desarrollado su derecho fundamental de acceso a la educación a través de las aulas virtuales construidas por la Junta de Castilla y León para cada centro educativo.

La imposibilidad de los estudiantes de esta parte de España para ejercer su derecho constitucional se encontraba en que no disponían de hardware que les permitiese acceder a tales aulas virtuales.

Ante la situación en la que se encontraban muchos estudiantes, los equipos directivos de los centros afectados realizaron un estudio para conocer la realidad exacta de las posibilidades de acceso de sus estudiantes a los dispositivos digitales desde sus domicilios. Una vez conocidos los resultados de las encuestas realizadas a estudiantes y sus familias, los equipos directivos de los centros afectados optaron por prestar hardware informático de sus propios centros a estudiantes sin acceso a dispositivos digitales en sus domicilios. Ciertamente, solo un $12 \%$ de las familias declaró en la encuesta que no poseía ordenador en sus domicilios. Este hecho, aunque es poco representativo en la masa de estudiantes de Castilla y León, ha puesto de manifiesto la falta de equipos informáticos en gran parte del alumnado sometido a estudio.

Otro dato reseñable es que, entre los estudiantes que sí tenían acceso a un ordenador en casa, ese tenía que compartirse con otros miembros de la familia 
M. ${ }^{a}$ DEL PILAR QUICIOS GARCÍA, PABLO HERRERO TEIJÓN Y PATRICIA GONZÁLEZ OCEJO

LA EFICACIA DE LA ENSEÑANZA A DISTANCIA DURANTE EL CONFINAMIENTO POR COVID-19

EN LAS ZONAS DE BAJA COBERTURA DE LA ESPAÑA VACIADA. EL CASO DE SALAMANCA

en un porcentaje del $30 \%$ de los alumnos. Esta falta de exclusividad del uso del dispositivo digital dificultaba enormemente el poder seguir la docencia de forma síncrona.

La metodología de la enseñanza a distancia suplió la limitación de seguir la formación de manera síncrona facilitando material de primera generación de enseñanza a distancia a los estudiantes que tenían esta dificultad. La forma de hacer llegar el material de la enseñanza a distancia se arbitró a través del servicio prestado por las autoridades locales y regionales, los ayuntamientos, la Guardia Civil y las fuerzas y cuerpos de seguridad del Estado. Todos se encargaron de transportar a los domicilios de los estudiantes los materiales de formación.

Uno de los mayores problemas a los que se tuvo que enfrentar una buena parte de la población enmarcada en la España vaciada era la falta de conexión a internet de banda ancha y/o fibra. El motivo de tal carencia se encontraba en la falta de rentabilidad de la inversión en fibra óptica en un territorio con escasa demanda y gran dispersión geográfica.

Esta debilidad podría ser superada, en no muchos años, por el $5 \mathrm{G}$ puesto que el coste de las torres de telecomunicaciones en las que se basa el $5 \mathrm{G}$ es mucho menor que el correspondiente despliegue de fibra óptica actual (Villares, 2020). Hasta que la implantación del 5G sea un hecho en la España vaciada, los estudiantes pueden aprovechar la etapa para formarse digitalmente puesto que entre el amplio abanico de debilidades encontradas durante el periodo de docencia no presencial llamó enormemente la atención la insuficiente formación en TIC del alumnado. Los estudiantes referían tener muchas dificultades a la hora de seguir las clases y subir las tareas al aula virtual de los distintos centros. Esta falta de formación se retroalimentaba por la falta de formación tecnológica de las familias de los estudiantes. Las familias refirieron de manera reiterada -en las encuestas de las que se han extraído los datos sobre los que se han apoyado las decisiones operativas de los equipos directivos- que no podían ayudar a sus hijos con las tareas de la enseñanza online por falta de conocimientos informáticos.

El periodo de docencia no presencial estuvo ampliamente condicionado por la implicación del profesorado. Este adaptó los contenidos de su programación, propuso distintas metodologías de educación a distancia en función de los medios y capacidades de los distintos alumnos y desplegó una auténtica y eficaz enseñanza personalizada e inclusiva que ha posibilitado a prácticamente la totalidad del alumnado de la España vaciada superar el curso escolar 2019/2020.

\section{REFERENCIAS BIBLIOGRÁFICAS}

Aparici, R. (1999). Mitos de la Educación a Distancia. En E. Martín y Q. Ahijado (Coords.), La educación a distancia en tiempos de cambio: nuevas generaciones, viejos conflictos (pp. 177-192). Madrid: Ediciones de la Torre.

Bachillerato a distancia (2020, 14 de octubre). https://cuadernodeorientacion.educa2.madrid. org/educacion-personas-adultas/ensenanza-distancia/bachillerato-distancia. 
M. ${ }^{\text {a }}$ DEL PILAR QUICIOS GARCÍA, PABLO HERRERO TEIJÓN Y PATRICIA GONZÁLEZ OCEJO LA EFICACIA DE LA ENSEÑANZA A DISTANCIA DURANTE EL CONFINAMIENTO POR COVID-19 EN LAS ZONAS DE BAJA COBERTURA DE LA ESPAÑA VACIADA. EL CASO DE SALAMANCA

Burillo, M. P. y Burillo, F. (2019). Las regiones desfavorecidas de España ante la Política de Cohesión 2021-2027. Asociación "Instituto de Investigación y Desarrollo Rural. Serranía Celtibérica». http://www.celtiberica.es/wpcontent/uploads/2019/04/6-Monografi \%CC \%81as-ISC-n \%C2 \%BA2-copia.pdf.

Cabero, J., Vázquez-Cano, E., López-Meneses, E. y Jaén, A. (2020). Posibilidades formativas de la tecnología aumentada. Un estudio diacrónico en escenarios universitarios. Revista Complutense de Educación, 31 (2), 134-154.

Ediciónmédica (2020, 12 de febrero). COVID-19 es el nombre oficial de la enfermedad por el nuevo coronavirus. https://www.edicionmedica.ec/secciones/salud-publica/covid19-nombre-oficial-de-la-enfermedad-por-el-nuevo-coronavirus-95307.

El Norte de Castilla (2020, 19 de abril). La Guardia Civil participa en la entrega de material escolar a alumnos de la provincia de Salamanca. https://www.elnortedecastilla.es/ salamanca/guardia-civil-participa-20200429173624-nt.html.

Enseñanza Secundaria Obligatoria a distancia (2020, 27 de octubre). http://www.madrid. org/dat_este/supe/ensenanzas-adultos/a_distancia.html

Europapress (2020, 29 de abril). La Guardia Civil colabora en la entrega de material escolar para alumnos de la provincia de Salamanca. https://www.europapress.es/castillay-leon/noticia-guardia-civil-colabora-entrega-material-escolar-alumnos-provincia-salamanca-20200429143417.html

Europapress (2020,15 de abril). La Junta repartirá 4.300 tarjetas SIM de datos entre alumnos con falta de conectividad a Internet. El Mundo. https://diariodecastillayleon.elmundo. es/articulo/castilla-y-leon/junta-repartira-4300-tarjetas-sim-datos-alumnos-falta-conectividad-internet/20200415182819007458.html.

Fernández, M. (2020). Jóvenes, despoblación y tecnología: la "España vaciada» se rebela. Agricultura: Revista Agropecuaria y Ganadera, 1036, 14-18.

Fombona, J., Pascual, M. Á. y Vázquez-Cano, E. (2020). Augmented reality: A new way to build knowledge. Bibliometric analysis and apps testing. IEEE Revista Iberoamericana de Tecnologías del Aprendizaje, 15 (1), 17-25.

Fuentes, C. (2019, 8 de diciembre). La brecha digital en la España rural: Salamanca tiene más de 700 "zonas blancas» sin cobertura de banda ancha y sin solución a medio plazo. Salamanca 24 horas. https://www.salamanca24horas.com/texto-diario/mos$\operatorname{trar} / 1650577 /$ desconexion-mundo-rural-salamanca-tiene-700-zonas-blancas-coberturabanda-ancha-solucion-medio-plazo.

García-Jiménez, A. (2020). La despoblación: una cuestión de Estado. Revista Jurídica de Castilla y León, 52, 31-72.

Giménez, A. (2017, 29 de abril). La España despoblada: la España sin cobertura. La Vanguardia. https://www.lavanguardia.com/politica/20170429/422140931449/la-espanadespoblada-la-espana-sin-cobertura.html

Martín, E. y Ahijado, M. (1999). La educación a distancia en tiempos de cambios: nuevas generaciones, viejos conflictos. Madrid: Ediciones La Torre.

Organización Panamericana de la Salud. Organización Mundial de la Salud. (2020, 11 de marzo). La OMS caracteriza la COVID-19 como una pandemia. https://www.paho.org/ es/noticias/11-3-2020-oms-caracteriza-covid-19-como-pandemia

Real Academia Española. (2020). Diccionario de la Lengua Española https://dle.rae.es/contenido/actualizaci \%C3 \%B3n-2020.

Reyes, A. J., Vallejos, M. L. y Quintana, D. A. (2020). Nueva realidad: compras en línea y a domicilio. Revista Odigos, 1 (3), 47-60. 
M. ${ }^{a}$ DEL PILAR QUICIOS GARCÍA, PABLO HERRERO TEIJÓN Y PATRICIA GONZÁLEZ OCEJO

LA EFICACIA DE LA ENSEÑANZA A DISTANCIA DURANTE EL CONFINAMIENTO POR COVID-19

EN LAS ZONAS DE BAJA COBERTURA DE LA ESPAÑA VACIADA. EL CASO DE SALAMANCA

Rodríguez, M. C. y Barragán, H. M. (2017). Entornos virtuales de aprendizaje como apoyo a la enseñanza presencial para potenciar el proceso educativo. Killkana Sociales: Revista de Investigación Científica, 1 (2), 7-14.

Rumble, G. y Harry, K. (1982). The distance teaching universities. London: Groom Helm.

Santano, A. C. (2020). Derechos humanos para el desarrollo de una sociedad realmente globalizada. Opinión Jurídica, 19 (38), 39-57.

Sevillano, M. L. y Quicios, M. P. (2009). La influencia del contexto en los usos de las herramientas virtuales. Teoría de la Educación. Educación y Cultura en la Sociedad de la Información, 10 (2), 86-107.

Vázquez, A. y Cambero, S. (Eds.). (2020). Reflexiones desconfinadas para la era posCOVID-19. Badajoz: AnthropiQa 2.0.

Vázquez-Cano, E. (2015). El reto de la formación docente para el uso de dispositivos digitales móviles en la educación superior. Perspectiva Educacional, Formación de Profesores, 54 (1), 149-162.

Villares, D. J. (2020). El derecho a la educación digital y su imprescindible fundamento democrático. En XVIII Congreso de la Asociación de Constitucionalistas de España (ACE).

Wu, F. et al. (2020). A new coronavirus associated with human respiratory disease in China. Nature, 579, 265-369.

Yang, P. y Wang, X. (2020). COVID-19: a new challenge for human beings. Cell Mol Immunol, 17, 555-557.

Zhou, P. et al. (2020). A pneumonia outbreak associated with a new coronavirus of probable bat origin. Nature, 579, 270-273. 
